\title{
The significance of immune-regulatory molecule B7-H4 in small cell lung cancer
}

\author{
Xiuqin Zhang ${ }^{1 \#}$, Shu Song ${ }^{2 \#}$, Fang Zhang ${ }^{1}$, Liming Cai ${ }^{1}$, Weiguo Xie ${ }^{3}$ \\ ${ }^{1}$ Department of Respiratory Medicine, Affiliated Hospital of Jiangnan University, Wuxi, China; ${ }^{2}$ Department of Pathology Medicine, Shanghai \\ Public Health Clinical Center, Fudan University, Shanghai, China; ${ }^{3}$ Department of Respiratory Medicine, The Affiliated Jiangyin Hospital of \\ Southeast University Medical College, Jiangyin, China \\ Contributions: (I) Conception and design: X Zhang, W Xie; (II) Administrative support: X Zhang; (III) Provision of study materials or patients: X \\ Zhang, S Song, W Xie; (IV) Collection and assembly of data: L Cai; (V) Data analysis and interpretation: F Zhang, S Song; (VI) Manuscript writing: \\ All authors; (VII) Final approval of manuscript: All authors. \\ \#These authors contributed equally to this work. \\ Correspondence to: Weiguo Xie. Department of Respiratory Medicine, the Affiliated Jiangyin Hospital of Southeast University Medical College, 163 \\ Shoushan Road, Jiangyin 214400, China. Email: 1831632102@qq.com.
}

\begin{abstract}
Background: B7-H4, a member of the B7 family, is detected in various cancers and is closely related to tumor development and prognosis. However, little is known about the clinical value of B7-H4 in small cell lung cancer (SCLC).

Methods: Immunohistochemical analysis was carried out on 103 SCLC specimens. The relationship between B7-H4 staining and the major clinical parameters of SCLC was analyzed, and the two-year survival rates were investigated by chi-square test.

Results: Only $5.83 \%$ of the SCLC specimens tested positive for B7-H4. B7-H4 was detected on the membrane and in the cytoplasm of tumor cells. In contrast, B7-H4 expression was not detected in normal lung tissue samples. B7-H4 was not found to be associated with major clinical parameters, such as tumor size, gender, age, smoking status, limited/extensive stage, tumor node metastasis, Karnofsky Performance Status, lymph node metastasis status, distant metastasis, or ki-67. Moreover, no obvious differences were observed in the two-year survival rates of B7-H4 positive or B7-H4-negative SCLC patients.

Conclusions: There is no correlation between $\mathrm{B} 7-\mathrm{H} 4$ expression and the proliferation or progression of SCLC. Therefore, B7-H4 is not a useful biomarker for SCLC prognosis.
\end{abstract}

Keywords: B7-H4; biomarker; immunohistochemistry (IHC); prognosis; small cell lung cancer (SCLC)

Submitted Mar 13, 2020. Accepted for publication Jun 23, 2020.

doi: 10.21037/apm-20-946

View this article at: http://dx.doi.org/10.21037/apm-20-946

\section{Introduction}

Small cell lung cancer (SCLC) is a common type of metastatic lung tumor, which accounts for approximately $15 \%$ of lung cancer cases diagnosed each year (1). With high malignancy, SCLC displays strong metastatic potential. Traditional chemotherapy and radiation therapy have been used to treat SCLC for decades; however, their success is limited and SCLC patients generally have a poor prognosis $(2,3)$.

Immunotherapy has achieved success as a treatment for different types of tumor, including lung cancer. Immune checkpoint inhibitors that block the programmed death 1 (PD-1)/programmed death ligand 1 (PD-L1) pathway have demonstrated significant therapeutic benefit in patients with non-small cell lung cancer (NSCLC) $(4,5)$. Immune targeted medicines such as nivolumab (a PD-1 inhibitor) have been used as second-line therapy for SCLC (6). 
Table 1 B7-H4 expression in SCLC tissues and normal lung tissues

\begin{tabular}{lcccc}
\hline \multirow{2}{*}{ Group } & Cases & \multicolumn{2}{c}{ B7-H4 } & Positive \\
\cline { 3 - 4 } & & $\begin{array}{c}\text { Negative } \\
\text { cases }\end{array}$ & $\begin{array}{c}\text { Positive } \\
\text { cases }\end{array}$ & cases (\%) \\
\hline SCLC & 103 & 6 & 97 & 5.83 \\
Normal lung & 40 & 0 & 40 & 0 \\
\hline
\end{tabular}

SCLC, small cell lung cancer.

However, the role of other B7 family molecules, such as B7-H4, in SCLC is still largely unknown, and it is yet to be determined whether targeting $\mathrm{B} 7-\mathrm{H} 4$ or its ligand offers therapeutic benefits for SCLC patients. Therefore, we investigated the usefulness of $\mathrm{B} 7-\mathrm{H} 4$ as a marker to predict progression and survival in SCLC. We present the following article in accordance with the REMARK reporting checklist (available at http://dx.doi.org/10.21037/apm-20-946).

\section{Methods}

One hundred and three specimens from SCLC patients were obtained by bronchoscopy or surgery at the Affiliated Hospital of Jiangnan University, the Affiliated Jiangyin Hospital of Southeast University Medical College, and the First People's Hospital of Yancheng Affiliated with Nantong University. None of the patients were undergoing radiation therapy or chemotherapy at the time the samples were collected. TNM staging was performed based on the International Association for the Study of Lung Cancer's (IASLC, 8th edition) staging system. The clinical features and survival times of the SCLC patients were recorded. Forty normal lung tissue samples were collected as controls. The study was conducted in accordance with the Declaration of Helsinki (as revised in 2013). The study received approval from the Ethics Committees at each of the three hospitals (the Affiliated Hospital of Jiangnan University, the Affiliated Jiangyin Hospital of Southeast University Medical College, and the First People's Hospital of Yancheng Affiliated with Nantong University). Informed consent was taken from all the patients.

\section{Immunobistochemistry (IHC)}

The SCLC specimens were analyzed by IHC (7). Briefly, wax-block specimens were cut into 4 - $\mu$ m-thick sections, before being dewaxed, dehydrated, and deparaffinized with alcohol at different concentrations. Antigens were retrieved by heating the slides at $100{ }^{\circ} \mathrm{C}$ in EDTA solution for $30 \mathrm{~min}$, and immersing them in hydrogen peroxide for $30 \mathrm{~min}$. Next, the slides were washed three times with phosphatebuffered saline, resuspended in a $3 \%$ BSA solution, and incubated with a polyclonal antibody against B7-H4 (clone: EP1165, 1:500 dilution, GeneTex, Inc. 2456 Alton Parkway Irvine, CA 92606, USA), and HRP-conjugated goat antirabbit IgG (Abcam, Cambridge, UK). Finally, the slides were incubated with diaminobenzidine and the images were captured.

\section{Evaluation of B7-H4 staining}

The stained sections underwent blind evaluation by two pathologists. The staining score was calculated based on the B7-H4 staining percentage and intensity. The staining percentage was scored as follows: $0(0 \%) ; 1(1-10 \%)$; 2 (11-33\%); 3 (34-66\%); and $4(67-100 \%)$. The staining intensity was scored as follows: 0 (no staining); 1 (weak staining, light yellow); 2 (moderate staining, yellowish brown); and 3 (strong staining, brown). A total score based on the staining percentage and intensity was calculated as follows: 0 (negative); 1-4 (weak positivity); 5-8 (moderate positivity); 9-12 (strong positivity). The negative group was defined as having scores $\leq 2$, whereas the positive group had scores >2) (8).

\section{Statistical analysis}

All statistical data was analyzed using SPSS 17.0 (SPSS Inc. Chicago, USA). The chi-square test was used to evaluate the correlation between $\mathrm{B} 7-\mathrm{H} 4$ staining and the major clinical parameters. A $\mathrm{P}$ value $<0.05$ represented statistical significance.

\section{Results}

\section{B7-H4 expression in SCLC}

A total of 103 SCLC specimens and 40 normal lung tissue samples were stained and analyzed by IHC. Positive B7-H4 staining was detected in $6(6 / 103,5.83 \%)$ SCLC specimens (Table 1). B7-H4 was expressed on the membrane and in the cytoplasm of tumor cells (Figure 1). In contrast, no B7-H4 expression was detected in the normal tissue lung samples (Table 1). 


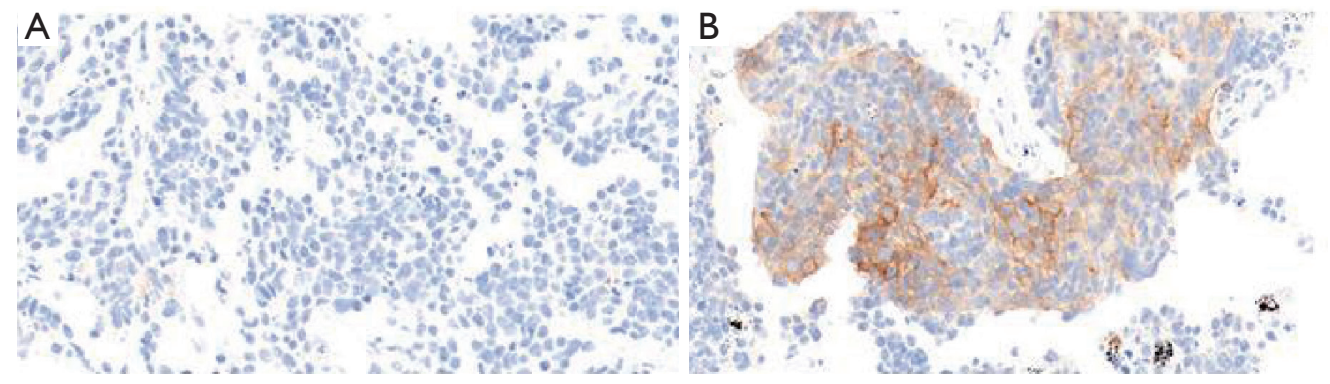

Figure 1 B7-H4 immunohistochemical staining in SCLC and normal lung tissues. (A) Negative staining at a magnification of $\times 400$; (B) positive staining at a magnification of $\times 400$. SCLC, small cell lung cancer.

\section{Relationship between B7-H4 staining and major clinical features}

There was no correlation identified between positive B7-H4 staining and major clinical parameters, such as tumor size, gender, age, smoking status, limited/extensive stage, tumor node metastasis, Karnofsky performance status, lymph node metastasis status, distant metastasis, or ki-67 (Table 2). In addition, the two-year survival rates of the $\mathrm{B} 7-\mathrm{H} 4$ positive and negative groups were compared and no difference was found (Table 2). These IHC results suggest that B7-H4 is not involved in the proliferation or progression of SCLC. In addition, B7-H4 was not a useful predictor of survival time in SCLC patients.

\section{Discussion}

B7-H4, also known as B7S1, VTCN1, or B7X, is often overexpressed in tumor tissues and tumor-associated macrophages (9). B7-H4 functions as a co-inhibitory molecule within the tumor microenvironment through binding to a receptor expressed on $\mathrm{T}$ cells; unfortunately, this receptor has not yet been defined (10-12). Nevertheless, based on its expression in various types of tumors, autoimmune diseases, inflammatory processes, pregnancy, and organ transplantation, $\mathrm{B} 7-\mathrm{H} 4$ has emerged as a promising new therapeutic target. The close correlation $\mathrm{B} 7$ $\mathrm{H} 4$ has with various diseases has been unveiled in previous studies (13-15).

$\mathrm{B} 7-\mathrm{H} 4$ is expressed in various cancers and demonstrates a significant correlation with tumor progression and development. The downregulation of B 7-H4 can increase caspase- 3 expression and decrease Bcl-2 protein expression. Meanwhile, B7-H4 over-expression promotes the proliferation and migration of colorectal carcinoma cells via the PI3K/Akt/mTOR signaling pathway (16).
By silencing B7-H4, survivin expression and cleavage of caspase-3/7 protein are increased, promoting hepatocellular carcinoma progression, both in vivo and in vitro (17). Immune regulatory molecules, including $\mathrm{B} 7-\mathrm{H} 4$, have been successfully used to predict breast cancer recurrence in stage I-III patients and have proved to be valuable biomarkers for predicting prognosis (18). Many studies have demonstrated a close relationship between $\mathrm{B} 7-\mathrm{H} 4$ and tumorigenesis.

The development of new blocking monoclonal antibodies that can alter the costimulatory signal between B7-H4 and its ligand within the tumor microenvironment, thus promoting tumor cell death, is an important goal in cancer therapy research. Targeting B7-H4 and its ligand, either alone or in combination with chemotherapy, holds potential therapeutic benefit for cancer patients (9). The Checkmate 067 clinical trials showed that nivolumab, either alone or in combination with ipilimumab, prolonged the progressionfree survival time in patients with metastatic melanoma (19). The Checkmate 227 clinical trials demonstrated that nivolumab in combination with ipilimumab had clinical benefits when used as first-line therapy for NSCLC, with longer progression-free survival compared with chemotherapy alone $(20,21)$. In contrast, it is still unknown whether immunotherapies to target the $\mathrm{B} 7-\mathrm{H} 4$ pathway could serve a purpose in SCLC treatment.

In the current study, B7-H4 expression was not significantly associated with SCLC clinical parameters, including survival time. In fact, $\mathrm{B} 7-\mathrm{H} 4$ was detected by IHC in only $5.83 \%$ of the SCLC specimens in our study. In line with our results, Carvajal et al. reported that several immune checkpoint molecules, including B7-H4, demonstrated limited clinical value as biomarkers, and that B7-H4 was detected in only $2.6 \%$ of SCLC cases by multiplexed quantitative immunofluorescence (22). Therefore, the clinical benefit of targeting the B7-H4 
Table 2 Association between B7-H4 expression and the clinicpathological parameters of SCLC patients

\begin{tabular}{|c|c|c|c|c|}
\hline \multirow[b]{2}{*}{ Characteristic } & \multirow[b]{2}{*}{ Cases } & \multicolumn{2}{|c|}{$\mathrm{B} 7-\mathrm{H} 4$} & \multirow[b]{2}{*}{$P$ value } \\
\hline & & $\begin{array}{c}\text { Negative } \\
\text { cases }\end{array}$ & $\begin{array}{c}\text { Positive } \\
\text { cases }\end{array}$ & \\
\hline Gender & & & & 0.871 \\
\hline Male & 80 & 76 & 4 & \\
\hline Female & 23 & 21 & 2 & \\
\hline Age (years) & & & & 0.426 \\
\hline$<65$ & 44 & 40 & 4 & \\
\hline$\geq 65$ & 59 & 57 & 2 & \\
\hline Smoking & & & & 0.587 \\
\hline Yes & 49 & 45 & 4 & \\
\hline No & 54 & 52 & 2 & \\
\hline Tumor size (cm) & & & & 1.000 \\
\hline$<5$ & 53 & 50 & 3 & \\
\hline$\geq 5$ & 50 & 47 & 3 & \\
\hline LS/ES-SCLC & & & & 1.000 \\
\hline LS-SCLC & 76 & 72 & 4 & \\
\hline ES-SCLC & 27 & 25 & 2 & \\
\hline KPS & & & & 0.501 \\
\hline$<70$ & 11 & 10 & 1 & \\
\hline$\geq 70$ & 92 & 87 & 5 & \\
\hline TNM stage & & & & 0.670 \\
\hline$I+I I$ & 19 & 17 & 2 & \\
\hline III + IV & 84 & 80 & 4 & \\
\hline Nodal metastasis & & & & 1.000 \\
\hline No & 10 & 10 & 0 & \\
\hline $\mathrm{N} 1+\mathrm{N} 2+\mathrm{N} 3$ & 93 & 87 & 6 & \\
\hline Distant metastasis & & & & 1.000 \\
\hline Mo & 75 & 71 & 4 & \\
\hline M1 & 28 & 26 & 2 & \\
\hline Survival time & & & & 0.503 \\
\hline$\leq 2$ years & 64 & 59 & 5 & \\
\hline$>2$ years & 39 & 38 & 1 & \\
\hline $\mathrm{Ki}-67$ & & & & 0.703 \\
\hline$<80 \%$ & 33 & 32 & 1 & \\
\hline$\geq 80 \%$ & 70 & 65 & 5 & \\
\hline
\end{tabular}

SCLC, small cell lung cancer. pathway in SCLC may be limited, as B7-H4 is not involved in the proliferation and progression of SCLC and cannot be used to predict SCLC prognosis and survival.

\section{Conclusions}

Although we analyzed only a limited number of specimens, the current study shows that B7-H4 expression offers a limited clinical value in SCLC and is not a useful biomarker for predicting the progression and survival of patients with the disease.

\section{Acknowledgments}

We would like to thank fellow pathologist Yan Qin for helping with the evaluation of the stained sections.

Funding: None.

\section{Footnote}

Reporting Checklist: The authors have completed the REMARK reporting checklist. Available at http://dx.doi. org/10.21037/apm-20-946

Data Sharing Statement: Available at http://dx.doi. org/10.21037/apm-20-946

Conflicts of Interest: All authors have completed the ICMJE uniform disclosure form (available at http://dx.doi. org/10.21037/apm-20-946). The authors have no conflicts of interest to declare.

Ethical Statement: The authors are accountable for all aspects of the work in ensuring that questions related to the accuracy or integrity of any part of the work are appropriately investigated and resolved. The study was conducted in accordance with the Declaration of Helsinki (as revised in 2013). The study received approval from the Ethics Committees at each of the three hospitals (the Affiliated Hospital of Jiangnan University, the Affiliated Jiangyin Hospital of Southeast University Medical College, and the First People's Hospital of Yancheng Affiliated with Nantong University). Informed consent was taken from all the patients. All charts and tables are original.

Open Access Statement: This is an Open Access article distributed in accordance with the Creative Commons Attribution-NonCommercial-NoDerivs 4.0 International 
License (CC BY-NC-ND 4.0), which permits the noncommercial replication and distribution of the article with the strict proviso that no changes or edits are made and the original work is properly cited (including links to both the formal publication through the relevant DOI and the license). See: https://creativecommons.org/licenses/by-nc-nd/4.0/.

\section{References}

1. Tsoukalas N, Aravantinou-Fatorou E, Baxevanos P, et al. Advanced small cell lung cancer (SCLC): new challenges and new expectations. Ann Transl Med 2018;6:145.

2. Farago AF, Keane FK. Current standards for clinical management of small cell lung cancer. Transl Lung Cancer Res 2018;7:69-79.

3. Badiyan SN, Roach MC, Chuong MD, et al. Combining immunotherapy with radiation therapy in thoracic oncology. J Thorac Dis 2018;10:S2492-507.

4. Bobbio A, Alifano M. Immune therapy of non-small cell lung cancer. The future. Pharmacol Res 2015;99:217-22.

5. Corrales L, Scilla K, Caglevic C, et al. Immunotherapy in Lung Cancer: A New Age in Cancer Treatment. Adv Exp Med Biol 2018;995:65-95.

6. Widick P, Gill RR, Mantia C, et al. Extensive-Stage SmallCell Lung Cancer With Sustained Complete Response to Single-Agent Nivolumab and Immune-Related Dermatitis. Clin Lung Cancer 2020;21:e6-9.

7. Chen L, Feng J, Xu B, et al. B7-H6 expression in human hepatocellular carcinoma and its clinical significance. Cancer Cell Int 2018;18:126.

8. Ceeraz S, Nowak EC, Noelle RJ. B7 family checkpoint regulators in immune regulation and disease. Trends Immunol 2013;34:556-63.

9. Podojil JR, Miller SD. Potential targeting of B7-H4 for the treatment of cancer. Immunol Rev 2017;276:40-51.

10. Kaur G, Janakiram M. B 7 $\mathrm{x}$-from bench to bedside. ESMO Open 2019;4:e000554.

11. Ogawa S, Abe R. Signal Transduction Via Co-stimulatory and Co-inhibitory Receptors. Adv Exp Med Biol

Cite this article as: Zhang X, Song S, Zhang F, Cai L, Xie W. The significance of immune-regulatory molecule B7-H4 in small cell lung cancer. Ann Palliat Med 2020;9(4):1953-1957. doi: 10.21037/apm-20-946
2019;1189:85-133.

12. Sica GL, Choi IH, Zhu G, et al. B7-H4, a molecule of the B7 family, negatively regulates $T$ cell immunity. Immunity 2003;18:849-61.

13. John P, Wei Y, Liu W, et al. The B7x Immune Checkpoint Pathway: From Discovery to Clinical Trial. Trends Pharmacol Sci 2019;40:883-96.

14. Yamaura $\mathrm{K}$, Watanabe $\mathrm{T}$, Boenisch $\mathrm{O}$, et al. In vivo function of immune inhibitory molecule $\mathrm{B} 7-\mathrm{H} 4$ in alloimmune responses. Am J Transplant 2010;10:2355-62.

15. Janakiram M, Shah UA, Liu W, et al. The third group of the B7-CD28 immune checkpoint family: HHLA2, TMIGD2, B7x, and B7-H3. Immunol Rev 2017;276:26-39.

16. Li C, Zhan Y, Ma X, et al. B7-H4 facilitates proliferation and metastasis of colorectal carcinoma cell through $\mathrm{PI} 3 \mathrm{~K} / \mathrm{Akt} / \mathrm{mTOR}$ signaling pathway. Clin Exp Med 2020;20:79-86.

17. Dong L, Xie L, Li M, et al. Downregulation of B7-H4 suppresses tumor progression of hepatocellular carcinoma. Sci Rep 2019;9:14854.

18. Lee DW, Ryu HS, Jin MS, et al. Immune recurrence score using 7 immunoregulatory protein expressions can predict recurrence in stage I-III breast cancer patients. $\mathrm{Br} \mathrm{J}$ Cancer 2019;121:230-6.

19. Larkin J, Chiarion-Sileni V, Gonzalez R, et al. Combined Nivolumab and Ipilimumab or Monotherapy in Untreated Melanoma. N Engl J Med 2015;373:23-34.

20. Hellmann MD, Ciuleanu TE, Pluzanski A, et al. Nivolumab plus Ipilimumab in Lung Cancer with a High Tumor Mutational Burden. N Engl J Med 2018;378:2093-104.

21. Dempke WCM, Fenchel K, Dale SP. Programmed cell death ligand-1 (PD-L1) as a biomarker for non-small cell lung cancer (NSCLC) treatment-are we barking up the wrong tree? Transl Lung Cancer Res 2018;7:S275-9.

22. Carvajal-Hausdorf D, Altan $M$, Velcheti V, et al. Expression and clinical significance of PD-L1, B7-H3, B7$\mathrm{H} 4$ and TILs in human small cell lung Cancer (SCLC). J Immunother Cancer 2019;7:65. 